\title{
Option-Implied Volatilities and Stock Returns: Evidence from Industry-Neutral Portfolios
}

\author{
Xiaoquan Liu, Eddie S.Y. Pong, Mark B. Shackleton, \\ AND YUANYUAN ZHANG
}

\begin{abstract}
Xiaoquan LiU
is an associate professor in finance at the University of Nottingham in Ningbo, China.

xiaoquan.liu@nottingham.edu.cn
\end{abstract}

EdDIE S.Y. Pong

is the director of research and analytics at the FTSE Group in Hong Kong. eddie.pong@ftse.com

MARK B. Shackleton is a professor of finance at Lancaster University, Lancaster, U.K. m.shackleton@lancaster.ac.uk

YUANYUAN ZHANG is an assistant professor of finance at Lingnan University in Hong Kong. zhangy@In.edu.hk

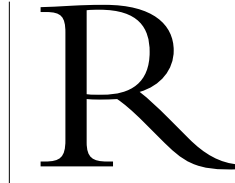

ecently, a number of studies ${ }^{1}$ have demonstrated the profitability of stock portfolios formed according to various option-implied measures. These articles typically construct portfolios by sorting all listed stocks according to certain volatility or skewness measures inferred from stockoption prices. Although shown to generate significant risk-adjusted returns, the trading strategies implemented in these studies are likely to be subject to industry effects.

In many portfolio and risk management strategies, being industry-neutral plays an important role. According to the multi-index model of Moskowitz and Grinblatt [1999], stock returns are considered to contain industry-specific components that are orthogonal to either market- or firmspecific components. Industry effects have been identified by market practitioners, especially institutional investors, as a key factor in constructing equity portfolios, and have been modeled and empirically tested in the context of asset pricing (e.g., Moskowitz and Grinblatt [1999] and Bali et al. [2006]).

This study aims to bridge the gap between the option pricing literature and the portfolio management literature by exploring the effect of industries on the informational efficiency of option-implied measures - that is, volatility skew and volatility spread-in predicting stock returns.
Motivated by industry-based valuation and trading practice in investment banks and hedge funds, Bali et al. [2006] examine industry effects on stock valuation and portfolio construction. They find that stock returns on industry-neutral contrarian portfolios are significantly positive and persistent. In addition, an industry-neutral investment strategy is far superior, in terms of the Sharpe ratio, to an industry-exposed full-universe strategy. Daniel and Titman [2012, p. 7] also suggest that portfolios formed based on industry membership "exhibit variation in factor loading relative to a number of macroeconomic factors but this variation is, at least to some extent, unrelated to book-to-market ratios." To the best of our knowledge, the only previous study that considers industry effects in the context of stock-return forecast and return skewness is that of Zhang [2005], who finds that portfolios formed according to the average skewness of firms in each industry can provide significant abnormal returns. The article suggests the existence of industry effects on return skewness and portfolio construction but, unlike our article, it adopts the skewness measure calculated from historical daily stock returns.

Our consideration of industry effects is also motivated by the growing literature investigating the time-varying correlation between asset returns and the role of correlation risk in asset pricing (e.g., Moskowitz 
[2003]; Driessen et al. [2009]; and Pollet and Wilson [2010]). The correlation between the returns of different stocks is stronger during market downturns (Longin and Solnik [2001]), especially for stocks in the same sector. Therefore, neutralizing the industry factor in portfolio construction helps improve portfolio performance.

Among recent studies that examine the lead-lag information relation between options and stock markets, Xing et al. [2010] explore the predictability and information content of volatility skew, defined as the difference between the implied volatility inferred from out-of-the-money (OTM) put options and that from at-the-money (ATM) call options. They sort all sample firms into quintile portfolios based on volatility skew, and construct zero-cost portfolios by buying those firms with the lowest skew and selling those with the highest. Their strategy generates positive and significant riskadjusted returns and suggests that stocks exhibiting the steepest volatility smirk in their equity options underperform those with the least pronounced volatility smirk.

In a related study, Cremers and Weinbaum [2010] examine whether volatility spread helps forecast future stock returns, where volatility spread is defined as the difference between the implied volatilities of ATM call and ATM put options. They show that stocks with relatively expensive calls significantly outperform those with relatively expensive puts. Doran and Krieger [2010] compare the stock-return predictabilities of alternative volatility measures and find that, after controlling for firm characteristics, the forecasting ability of volatility spread is stronger than that of volatility skew.

The predictability of volatility skew and volatility spread is consistent with the informed trading models of Easley et al. [1998] and Gârleanu et al. [2009], who show that when information asymmetry exists between options and stock markets, informed trading will take place in the options market first. Informed option traders could thus raise the demand of certain option contracts and affect their prices.

Following previous studies, we first construct equity portfolios according to volatility skew and volatility spread, without controlling for industry effects. Consistent with extant evidence, these portfolios generate significant returns. However, we find that industry effects exert a nontrivial influence on these portfolios, and the effect is greater for portfolios formed according to volatility skew.
We then form industry-neutral portfolios, net of industry exposure, and compare their performance with that of the full-universe portfolios constructed from all available stocks, regardless of industry. Consistent with the literature on option informativeness, industry-neutral portfolios thus formed always generate positive and significant returns. Meanwhile, neutralizing industry effects reduces portfolio risk, especially downside risk. When the holding period is one week, the industryneutral approach generates higher $t$-statistics and Sortino ratios $^{2}$ than the full-universe approach for all cases of volatility skew and most cases of volatility spread. The results of longer holding periods, from one month to six months, provide stronger support that industry-neutral portfolios dominate industry-exposed ones with higher $t$-statistics and Sortino ratios and lower standard deviations, regardless of the volatility measure.

Our results also show that the full-universe portfolios are significantly subject to the effects of the industries that perform badly during periods of market turbulence, and therefore suffer substantial downside risk. During the market crashes of the dot-com bubble (from 1999 to 2001) and the banking crisis (from 2008 to 2011), industry-neutral portfolios consistently outperformed full-universe ones by providing higher returns, $t$-statistics, and Sortino ratios. This finding is of particular importance to institutional investors and fund managers, because it provides strong evidence of a simple way to enhance portfolio performance when the market is in a meltdown.

\section{DATA AND VOLATILITY MEASURES}

We obtain option data from OptionMetrics' Ivy DB database, which includes daily closing quotes at the Chicago Board Options Exchange (CBOE) for all U.S.listed index and equity options. We obtain daily stock data, including total return and trading volume, from the Center for Research in Security Prices (CRSP). Our sample period is from January 1996 to December 2011.

We apply the same filter rules to option data as Xing et al. [2010] and use only option contracts with 1) time to maturity between 10 and 50 days, 2) an average of bid and ask quotes higher than $\$ 0.125$, and 3 ) an implied volatility between 0.03 and 2 . Meanwhile, we remove any option observation with zero open interest or missing trading volume from the sample. In addi- 
tion, we exclude stocks with closing prices below $\$ 5$ or trading volumes that are not positive. Call and put options with moneyness (strike-to-spot ratio) closest to one, but between 0.95 and 1.05 are defined as ATM options, and put options with moneyness closest to 0.95 , but between 0.8 and 0.95 are defined as OTM put options. We use the implied volatilities provided by the Ivy DB database directly, which are derived from the midpoint of the most competitive bid and ask quotes and computed via a binomial tree model. ${ }^{3}$ When there is more than one ATM call, ATM put, or OTM put in a trading day, we take the average of implied volatilities, either weighted by option trading volume or equally weighted, to compute a single daily observation.

Let $\mathrm{IV}_{\mathrm{C}, \mathrm{ATM}}, \mathrm{IV}_{\mathrm{P}, \mathrm{ATM}}$, and $\mathrm{IV}_{\mathrm{P}, \mathrm{OTM}}$, respectively, denote the daily implied volatilities of ATM call, ATM put, and OTM put options for each firm. The volatility skew, SKEW, of Xing et al. [2010] is estimated as

$$
\mathrm{SKEW}=\mathrm{IV}_{\mathrm{P}, \mathrm{OTM}}-\mathrm{IV}_{\mathrm{C}, \mathrm{ATM}}
$$

The volatility spread, SPREAD, is estimated as ${ }^{4}$

$$
\text { SPREAD }=\mathrm{IV}_{\mathrm{P}, \mathrm{ATM}}-\mathrm{IV}_{\mathrm{C}, \mathrm{ATM}}
$$

If the implied volatilities are weighted by option trading volume (or equally weighted), we denote volatility skew as SKEW_VW (or SKEW_EW) and volatility spread as SPREAD_VW (or SPREAD_EW). Because some options in our sample have zero trading volume, the sample sizes of SKEW_VW and SPREAD_VW are smaller than those of SKEW_EW and SPREAD_EW. The weekly observations (from Tuesday close to Tuesday close) are the averages of daily estimates when there are at least two daily estimates within a week. We then skip one day to construct equally weighted stock portfolios ${ }^{5}$ for the next week (from Wednesday close to Wednesday close) to avoid microstructure issues arising from nonsynchronous trading. ${ }^{6}$ We group firms on the basis of two-digit Standard Industrial Classification (SIC) codes and include all industries that contain at least five firms in a week. ${ }^{7}$

\section{INDUSTRY EXPOSURE}

Exhibit 1 provides summary statistics for our data. Each week we also calculate industry SKEW (or SPREAD) by averaging the SKEW (or SPREAD) values of the firms within each industry. The mean and median values of SKEW and SPREAD of individual firms are qualitatively similar to those reported by Xing et al. [2010] and Cremers and Weinbaum [2010]. The values of the industry average SKEW and SPREAD are much less volatile than those of individual firms. For example, the standard deviation of SKEW_VW Aggregate is $4.63 \%$ across all firm-week observations, while that of SKEW_VW Industry is only $2.32 \%$. Overall, the estimates of SPREAD show less variation than SKEW. The average numbers of industries each week are 18 for SKEW_VW Industry and 35 for SKEW_EW Industry, and 26 and 45 for SPREAD_VW Industry

\section{E X H I B I T 1}

\begin{tabular}{|c|c|c|c|c|c|c|c|c|}
\hline & & Mean & $\begin{array}{l}\text { Standard } \\
\text { Deviation }\end{array}$ & $25 \%$ & Median & $75 \%$ & $\begin{array}{c}\text { Number of } \\
\text { Observations }\end{array}$ & $\begin{array}{c}\text { Average Number of } \\
\text { Observations } \\
\text { Each Week }\end{array}$ \\
\hline \multirow[t]{2}{*}{ SKEW_VW } & Aggregate & 5.81 & 4.63 & 3.33 & 5.17 & 7.55 & 306,072 & 368 \\
\hline & Industry & 5.92 & 2.32 & 4.39 & 5.52 & 7.07 & 15,229 & 18 \\
\hline \multirow[t]{2}{*}{ SKEW_EW } & Aggregate & 5.57 & 5.54 & 2.77 & 4.60 & 7.13 & 725,887 & 872 \\
\hline & Industry & 5.71 & 2.29 & 4.21 & 5.37 & 6.86 & 29,498 & 35 \\
\hline \multirow[t]{2}{*}{ SPREAD_VW } & Aggregate & 1.08 & 3.37 & -0.09 & 0.68 & 1.69 & 468,632 & 563 \\
\hline & Industry & 1.03 & 1.17 & 0.41 & 0.84 & 1.43 & 21,715 & 26 \\
\hline \multirow[t]{2}{*}{ SPREAD_EW } & Aggregate & 0.99 & 4.04 & -0.29 & 0.52 & 1.79 & $1,099,494$ & 1322 \\
\hline & Industry & 1.01 & 1.35 & 0.31 & 0.82 & 1.52 & 37,147 & 45 \\
\hline
\end{tabular}

Summary Statistics of Weekly Estimates of Volatility Skew and Volatility Spread

Note: Daily observations of SKEW and SPREAD of firms are estimated as the averages of implied volatilities, either weighted by option trading volume $(V W)$ or equally weighted $(E W)$. Weekly estimates of industry SKEW and SPREAD are the averages across firms in each industry when there are no fewer than five firms in the industry in the week. Industries are defined using two-digit SIC codes. All numbers are in percent, except the number of observations. "Aggregate" denotes all firm-weeks; "Industry" denotes the industry average. 
and SPREAD_EW Industry, respectively. The volatility spread has more observations than volatility skew, due to the fact that the sample includes more available ATM put options than OTM put options. The number of observations increases dramatically over time as more options become actively traded. For example, the weekly average numbers of industries in our sample for SKEW_VW are, respectively, 8, 16, and 28 during 1996 to 2000, 2001 to 2005, and 2006 to 2011.

The average volatility skew (or volatility spread) across firms within an industry is a rough representative of the industry's SKEW (or SPREAD). We also directly examine the distributions of volatility skew and volatility spread within each industry and compare them with the distributions in the full universe. To this end, we calculate the aggregate median, which is the median value of SKEW (or SPREAD) across all firms in the full universe, irrespective of industry, and the industry median, which is the median value across firms within a specific industry. For each firm, we estimate the absolute deviations of SKEW (or SPREAD) from the aggregate median and from the corresponding industry median. In doing so, we could compare the distributions of individual volatility skew (or volatility spread) within industries with those in the full universe. We expect, on average, higher dispersions from the aggregate median than from the industry median. Exhibit 2 reports the descriptive statistics of weekly median dispersions across firms.
For both volatility skew and volatility spread, the statistics (except for standard deviations) of the dispersions from the industry median are always less than those from the aggregate median, indicating that these observations are more concentrated within each industry, compared to their distributions in the full universe, and distribute more closely to the industry median than to the aggregate median. The null hypothesis that the difference between weekly dispersions from the aggregate median and from the industry median is zero or negative is always rejected at the $1 \%$ significance level, for both SKEW and SPREAD. Between the two measures, SKEW has greater dispersions than SPREAD does, consistent with the findings of Doran and Krieger [2010] that firm-specific characteristics have stronger effects on SKEW than on SPREAD. Therefore, there are clear industry effects that make the estimates of SKEW and SPREAD distribute more closely within industries than in the whole sample.

We then construct quintile portfolios following Xing et al. [2010] and Cremers and Weinbaum [2010], and estimate their industry exposures. Each week we sort sample firms into five portfolios, according to SKEW (or SPREAD). Portfolio 1 includes firms in the bottom quintile with the lowest volatility skew (or volatility spread), and portfolio 5 includes those in the top quintile with the highest values. We take a long position in portfolio 1 and a short position in portfolio 5 .

\section{E X H I B I T 2}

The Dispersion of Volatility Skew and Volatility Spread Across Industry Sectors

\begin{tabular}{|c|c|c|c|c|c|c|c|c|}
\hline & & Mean & $\begin{array}{l}\text { Standard } \\
\text { Deviation }\end{array}$ & Minimum & $25 \%$ & Median & $75 \%$ & Maximum \\
\hline \multirow[t]{2}{*}{ SKEW_VW } & Aggregate median & 1.83 & 0.46 & 0.92 & 1.49 & 1.73 & 2.12 & 4.26 \\
\hline & Industry median & 1.64 & 0.47 & 0.77 & 1.30 & 1.52 & 1.94 & 3.94 \\
\hline \multirow[t]{2}{*}{ SKEW_EW } & Aggregate median & 2.00 & 0.54 & 1.07 & 1.59 & 1.90 & 2.35 & 4.29 \\
\hline & Industry median & 1.85 & 0.53 & 0.98 & 1.43 & 1.72 & 2.21 & 3.99 \\
\hline \multirow[t]{2}{*}{ SPREAD_VW } & Aggregate median & 1.02 & 0.42 & 0.44 & 0.69 & 0.88 & 1.35 & 2.83 \\
\hline & Industry median & 0.96 & 0.40 & 0.41 & 0.65 & 0.82 & 1.28 & 2.79 \\
\hline \multirow[t]{2}{*}{ SPREAD_EW } & Aggregate median & 1.18 & 0.58 & 0.44 & 0.71 & 0.93 & 1.75 & 3.20 \\
\hline & Industry median & 1.14 & 0.55 & 0.41 & 0.68 & 0.90 & 1.68 & 2.94 \\
\hline
\end{tabular}

Note: Each week we calculate the aggregate median, the median value of SKEW (or SPREAD) across all firms in the full universe, and the industry median, the median value across the firms within each industry. The weekly dispersion is the median of the absolute deviations of individual SKEW (or SPREAD) from either the aggregate median or the industry median. We estimate the daily observations of SKEW and SPREAD from the averages of the implied volatilities, either weighted by option trading volume $(V W)$ or equally weighted $(E W)$. All numbers are percentages. 
To determine whether this quintile strategy is exposed to industry effects, we compute the respective percentages of stocks belonging to industry $i$ in portfolios 1 and 5 each week. The quintile strategy's net industry exposure to industry $i$ is the absolute difference between the two percentages. The sum of net exposures across all industries in a week is the total net exposure. If the volatility skew (or volatility spread) of individual firms exhibits very strong industry-specific characteristics in a week, all the stocks in portfolio 1 may belong to one industry, while portfolio 5 contains only stocks of another industry. With no industry overlap, the total net exposure is $200 \%$. On the other hand, if portfolios 1 and 5 include stocks that are spread over the same set of industries, the industry effects of the two portfolios will offset each other and the net exposure will be zero.

Exhibit 3 tabulates descriptive statistics of the weekly total net exposure, the weekly number of industries with non-zero net exposure, denoted by $\mathrm{N}$, and the weekly proportion of industries that contribute to $80 \%$ of the total net exposure, denoted by N80. ${ }^{8}$ On average, the total net exposure is $90.36 \%$ for the portfolios sorted by SKEW_VW, and $74.82 \%$ for those sorted by SPREAD_VW. The first quartiles for SKEW_VW and SPREAD_VW are $76.52 \%$ and $65.58 \%$, respec- tively. For SKEW_EW and SPREAD_EW, the means of total net exposure are slightly lower, but still more than a quarter of the full exposure of $200 \%$. The means of N80 range from $44.05 \%$ to $54.24 \%$, showing that, on average, approximately $50 \%$ of industries contribute to the majority $(80 \%)$ of industry exposure. ${ }^{9}$ These statistics suggest that the portfolios constructed by the conventional strategy, adopted in prior literature, are subject to industry effects. Therefore, neutralizing industry effects when constructing portfolios according to volatility skew and volatility spread helps improve portfolio performance.

\section{PORTFOLIO PERFORMANCE OVER THE NEXT WEEK}

We compare the performance of industry-neutral portfolios based on SKEW and SPREAD with industryexposed, full-universe portfolios. Following Bali et al. [2006], we adopt a pair-trading strategy, for which the industry-neutral and full-universe portfolios always involve the same number of stocks. Suppose $m_{t}$ industries are available in week $t$. The industry-neutral approach involves buying $n$ stocks with the lowest SKEW (or SPREAD) and selling $n$ stocks with the highest SKEW (or SPREAD) in each of the $m_{t}$ industries..$^{10}$ The port-

\section{E X H I B I T 3}

\section{Industry Exposure of the Quintile Portfolio Strategy Based on the Full Universe of Firms}

\begin{tabular}{lllcccc}
\hline & Mean & $\begin{array}{c}\text { Standard } \\
\text { Deviation }\end{array}$ & $\mathbf{2 5 \%}$ & Median & $\mathbf{7 5 \%}$ \\
\hline SKEW_VW & Industry exposure & $90.36 \%$ & $18.88 \%$ & $76.52 \%$ & $90.50 \%$ & $102.77 \%$ \\
& $\mathrm{~N}$ & 33.40 & 10.04 & 25 & 33 & 42 \\
& N80 & $54.24 \%$ & $9.14 \%$ & $47.06 \%$ & $53.85 \%$ & $61.11 \%$ \\
SKEW_EW & Industry exposure & $69.03 \%$ & $12.27 \%$ & $60.78 \%$ & $67.57 \%$ & $76.74 \%$ \\
& $\mathrm{~N}$ & 50.42 & 6.28 & 47 & 51 & 55 \\
& N80 & $46.79 \%$ & $6.57 \%$ & $42.11 \%$ & $46.30 \%$ & $50.91 \%$ \\
SPREAD_VW & Industry exposure & $74.82 \%$ & $12.50 \%$ & $65.58 \%$ & $74.04 \%$ & $83.09 \%$ \\
& $\mathrm{~N}$ & 40.93 & 10.19 & 32 & 41 & 50 \\
& N80 & $50.68 \%$ & $8.88 \%$ & $44 \%$ & $50 \%$ & $57.69 \%$ \\
SPREAD_EW & Industry exposure & $54.23 \%$ & $8.19 \%$ & $48.52 \%$ & $54.07 \%$ & $59.13 \%$ \\
& $\mathrm{~N}$ & 55.85 & 4.77 & 52 & 56 & 60 \\
& $\mathrm{~N} 80$ & $44.05 \%$ & $5.84 \%$ & $40 \%$ & $44.23 \%$ & $48 \%$ \\
\hline
\end{tabular}

Note: Each week we sort sample firms into quintile portfolios based on SKEW or SPREAD. Portfolio 1 includes the firms with the lowest values and portfolio 5 includes those with the highest. We then compute the respective percentages of stocks belong to industry i in portfolios 1 and 5 . The net exposure of the quintile portfolio to industry $i$ is the absolute difference between the two percentages. We sum the net exposures of all industries to obtain the weekly measure of industry exposure. The term $N$ refers to the number of industries that have non-zero net exposure in each week and N80 is the proportion of industries that contribute to $80 \%$ of total net exposure each week. The daily observations of SKEW and SPREAD are estimated by the averages of the implied volatilities, either weighted by option trading volume $(V W)$ or equally weighted $(E W)$. 
folio thus formed involves simultaneously buying and selling $m_{t} \times n$ stocks to cover all industries, as long as each is represented by no fewer than five firms in a week. The return series is not exposed to industry effects.

We also form portfolios regardless of industries, based purely on the rankings of SKEW (or SPREAD) across the full universe of sample firms. In week $t$, the full-universe approach involves buying $m_{t} \times n$ stocks with the lowest SKEW (or SPREAD) and selling $m_{t} \times n$ stocks with the highest SKEW (or SPREAD). The portfolio thus formed contains the same number of stocks as the industry-neutral counterpart, but may be substantially exposed to industry effects.

Exhibit 4 reports the results of the pair-trading strategy of one-week-ahead returns when the weekly number of stocks in each industry is $n=2$ (panel A) and $n=3$ (panel B). Assuming that investors are mean-variance optimizers, we report the mean, standard devia-

\section{E X H I B I T 4}

\section{Portfolio Performance With the Pair-Trading Strategy}

\begin{tabular}{|c|c|c|c|c|c|c|}
\hline Volatility Measures & Investment Approach & Mean Return & Standard Deviation & Skewness & Drawdown & Sortino Ratio \\
\hline \multicolumn{4}{|c|}{ Panel A: Number of Selected Stock in Each Industry $n=2$} & & & \\
\hline \multirow[t]{2}{*}{ SKEW_VW } & Full universe & $\begin{array}{l}0.27 \% \\
(2.30)\end{array}$ & $3.36 \%$ & -0.0213 & 0.8416 & 0.1189 \\
\hline & Industry neutral & $\begin{array}{l}0.28 \% \\
(3.89)\end{array}$ & $2.07 \%$ & 0.4937 & 0.2944 & 0.2215 \\
\hline \multirow[t]{2}{*}{ SKEW_EW } & Full universe & $\begin{array}{l}0.10 \% \\
(1.33)\end{array}$ & $2.23 \%$ & -0.2440 & 0.7353 & 0.0656 \\
\hline & Industry neutral & $\begin{array}{l}0.15 \% \\
(3.87)\end{array}$ & $1.13 \%$ & -0.0019 & 0.1779 & 0.2129 \\
\hline \multirow[t]{2}{*}{ SPREAD_VW } & Full universe & $\begin{array}{l}0.25 \% \\
(3.32)\end{array}$ & $2.13 \%$ & 0.1585 & 0.5686 & 0.1780 \\
\hline & Industry neutral & $\begin{array}{l}0.24 \% \\
(4.49)\end{array}$ & $1.56 \%$ & 0.4587 & 0.2355 & 0.2551 \\
\hline \multirow[t]{2}{*}{ SPREAD_EW } & Full universe & $\begin{array}{l}0.29 \% \\
(6.01)\end{array}$ & $1.41 \%$ & 0.1241 & 0.1184 & 0.3481 \\
\hline & Industry neutral & $\begin{array}{c}0.23 \% \\
(6.19)\end{array}$ & $1.05 \%$ & 0.2395 & 0.1180 & 0.3686 \\
\hline \multicolumn{7}{|c|}{ Panel B: Number of Selected Stock in Each Industry $n=3$} \\
\hline \multirow[t]{2}{*}{ SKEW_VW } & Full universe & $\begin{array}{l}0.20 \% \\
(2.05)\end{array}$ & $2.79 \%$ & 0.0250 & 0.6600 & 0.1057 \\
\hline & Industry-neutral & $\begin{array}{l}0.25 \% \\
(4.12)\end{array}$ & $1.76 \%$ & 0.1881 & 0.2776 & 0.2311 \\
\hline \multirow[t]{2}{*}{ SKEW_EW } & Full universe & $\begin{array}{l}0.12 \% \\
(1.89)\end{array}$ & $1.85 \%$ & -0.3060 & 0.5741 & 0.0944 \\
\hline & Industry neutral & $\begin{array}{l}0.16 \% \\
(4.53)\end{array}$ & $0.99 \%$ & 0.3012 & 0.1712 & 0.2584 \\
\hline \multirow[t]{2}{*}{ SPREAD_VW } & Full universe & $\begin{array}{l}0.23 \% \\
(3.64)\end{array}$ & $1.79 \%$ & 0.1754 & 0.4664 & 0.1985 \\
\hline & Industry neutral & $\begin{array}{l}0.16 \% \\
(3.53)\end{array}$ & $1.34 \%$ & 0.1843 & 0.2197 & 0.1913 \\
\hline \multirow[t]{2}{*}{ SPREAD_EW } & Full universe & $\begin{array}{l}0.22 \% \\
(5.15)\end{array}$ & $1.22 \%$ & -0.1524 & 0.1621 & 0.2818 \\
\hline & Industry neutral & $\begin{array}{l}0.19 \% \\
(6.41)\end{array}$ & $0.85 \%$ & 0.2295 & 0.0966 & 0.3860 \\
\hline
\end{tabular}

Note: In week $t$, for each of the $m_{t}$ industries, we buy $n$ stocks with the lowest SKEW (or SPREAD) and short $n$ stocks with the highest values. The industry-neutral portfolio thus involves simultaneously buying and shorting $m_{t} \times n$ stocks, covering all industries with at least five firms in the week. The full-universe portfolio involves buying $m_{t} \times n$ stocks with the lowest SKEW (or SPREAD) among all the firms and shorting $m \times n$ stocks with the highest, without considering industry differences. In panel $A$, the number of stocks bought and shorted within each industry per week is $n=2$; in panel $B, n=3$ if there are more than seven firms in the industry (otherwise $n=2$ ). The daily observations of SKEW and SPREAD are estimated by the averages of the implied volatilities, either weighted by option trading volume $(V W)$ or equally weighted $(E W)$. The numbers in parentheses are t-statistics. 
tion, $t$-statistics, skewness, ${ }^{11}$ maximum drawdown, ${ }^{12}$ and Sortino ratio of weekly returns to describe portfolio performance. We observe that the average weekly returns are positive and significantly different from zero in each case, except for the full-universe approach of SKEW_EW, with $n=2 .{ }^{13}$ Therefore, consistent with previous studies, volatility skew and volatility spread are suitable measures with which we can design profitable trading strategies.

For volatility skew, the industry-neutral approach is far superior to the full-universe approach in both panels. The $t$-statistics for the industry-neutral approach are much higher than those for the full-universe approach. For example, based on SKEW_VW, the $t$-statistic is 3.89 for the former, compared with 2.30 for the latter in panel A, and 4.12 compared with 2.05 , respectively, in panel $\mathrm{B}$. This is due to the lower portfolio risk measured by the standard deviation and higher portfolio returns generated by the industry-neutral approach. When $n=3$, the average weekly returns of the industryneutral portfolios are five and four basis points higher than those of the full-universe portfolios, respectively, for SKEW_VW and SKEW_EW. The Sortino ratios are also higher for the industry-neutral portfolios. Meanwhile, the industry-neutral portfolios exhibit lower downside risk, because they exhibit less negative skewness and a much smaller portfolio drawdown. Hence, the removal of industry effects has a material effect on the risk-return profile of portfolios formed based on volatility skew.

For volatility spread, the results are somewhat different. Being industry-neutral results in lower portfolio returns for both $n=2$ and $n=3$. However, the loss in average returns is surpassed by lower risk, especially lower downside risk. The $t$-statistics and Sortino ratios of the industry-neutral portfolios are always higher than those of the full-universe portfolios for SPREAD, except for one case of SPREAD_VW in panel B. ${ }^{14}$

Exhibit 5 plots the time series of weekly returns of the pair-trading strategy $(n=2)$ formed by the industry-neutral and full-universe approaches according to SKEW_VW. The weekly returns of the industry-neutral portfolio (solid line) are much less volatile than those of the full-universe portfolio (dotted line). Being industryneutral considerably reduces downside risk, particularly during 2000 and the credit crunch of $2008 .{ }^{15}$ The lowest weekly return of the full-universe portfolio in Exhibit 5 was $-13 \%$ in the week ending November 26, 2008, when total industry exposure was $148 \%$ and the highest net exposure was a long position of $31 \%$ in the industry of holding and other investment offices (SIC code 67). The corresponding industry-neutral portfolio generated a weekly return of $-4 \%$. In addition, the third-lowest weekly return of the full-universe portfolio was $-12 \%$ in the week ending May 23, 2000, during the dot-com bubble crash. The portfolio had a total industry exposure of $120 \%$ and a long exposure of $25 \%$ in the electronic equipment and components sector (SIC code 36). The corresponding industry-neutral portfolio generated a return of $-3 \%$ that week.

We further examine the robustness of our results by broadening our stock selection procedure. Following (among others) Xing et al. [2010] and Cremers and Weinbaum [2010], we adopt the quintile portfolio strategy described earlier. The portfolios thus constructed are based on the full universe of stocks and are subject to industry effects. We also sort stocks by SKEW (or SPREAD) within each industry into quintiles and form industry-neutral portfolios by buying the lowest quintiles and selling the highest for all industries with no fewer than five firms. By construction, the latter strategy contains stocks from all available industries and is not exposed to industry effects.

Exhibit 6 reports the quintile strategy's performance. We observe that, for full-universe portfolios sorted on SKEW and SPREAD, the average weekly returns are always highly significant, consistent with prior literature. Comparing the full-universe results of the quintile portfolio strategy with those of the pairtrading strategy in Exhibit 4, we find that the additional diversification gained by including more stocks in portfolios reduces the standard deviations in all cases. For portfolios sorted by SKEW_VW, SKEW_EW, and SPREAD_VW, the industry-neutral approach leads to higher $t$-statistics and Sortino ratios, lower risk (reflected in lower standard deviations), more positive (or less negative) skewness, and lower drawdowns than in the full-universe approach. The industry-neutral portfolio sorted by SPREAD_EW is shown to gain less negative return skewness, but has a lower $t$-statistic and Sortino ratio and larger drawdown than the fulluniverse portfolio. ${ }^{16}$

To summarize, for the one-week holding period, we find that industry-neutral portfolios formed by volatility skew and volatility spread have lower downside 


\section{E X H I B I T 5}

Time-Series Returns of the Pair-Trading Strategy Based on Volatility Skew
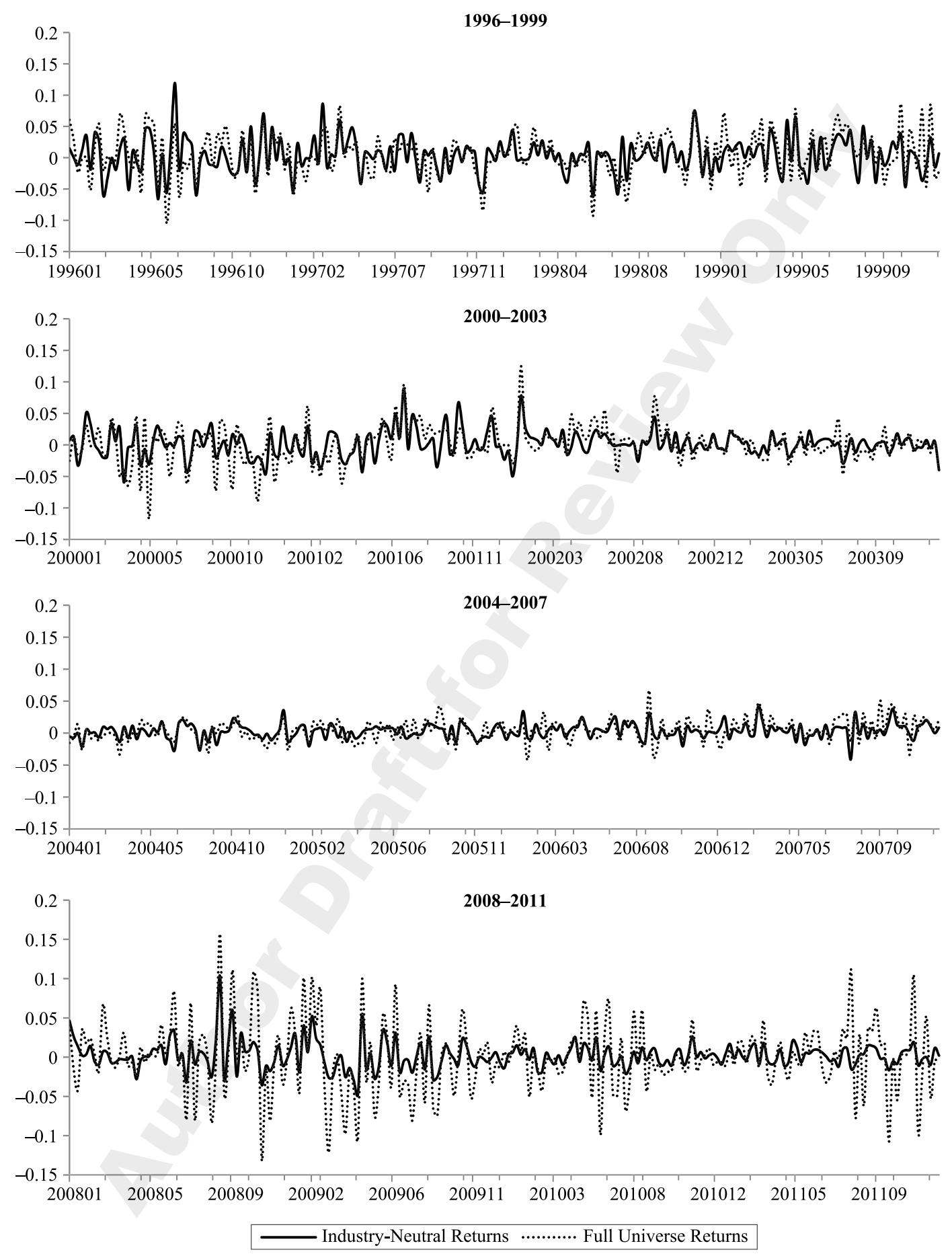

Note: Exhibit 5 plots the time-series returns of the pair-trading strategy formed by volatility skew $\left(S K E W_{-} V W\right)$ with $n=2$. See also the note for Exhibit 4. The solid line represents the weekly returns from the industry-neutral approach and the dotted line represents the weekly returns from the full-universe approach. The sample period is from January 1996 to December 2011. 


\section{E X H I B I T 6}

\section{Portfolio Performance with the Quintile Portfolio Strategy}

\begin{tabular}{|c|c|c|c|c|c|c|}
\hline $\begin{array}{l}\text { Volatility } \\
\text { Measures }\end{array}$ & $\begin{array}{l}\text { Investment } \\
\text { Approach }\end{array}$ & Mean Return & $\begin{array}{l}\text { Standard } \\
\text { Deviation }\end{array}$ & Skewness & Drawdown & Sortino Ratio \\
\hline \multirow[t]{2}{*}{ SKEW_VW } & Full universe & $\begin{array}{l}0.25 \% \\
(3.25)\end{array}$ & $2.20 \%$ & -0.0886 & 0.4748 & 0.1711 \\
\hline & Industry-neutral & $\begin{array}{l}0.27 \% \\
(4.25)\end{array}$ & $1.82 \%$ & 0.0081 & 0.2881 & 0.2339 \\
\hline \multirow[t]{2}{*}{ SKEW_EW } & Full universe & $\begin{array}{l}0.13 \% \\
(2.75)\end{array}$ & $1.39 \%$ & -0.5750 & 0.3240 & 0.1367 \\
\hline & Industry-neutral & $\begin{array}{l}0.12 \% \\
(3.41)\end{array}$ & $1.00 \%$ & -0.0536 & 0.1787 & 0.1829 \\
\hline \multirow[t]{2}{*}{ SPREAD_VW } & Full universe & $\begin{array}{l}0.16 \% \\
(3.28)\end{array}$ & $1.44 \%$ & -0.2162 & 0.3434 & 0.1719 \\
\hline & Industry-neutral & $\begin{array}{l}0.17 \% \\
(3.54)\end{array}$ & $1.35 \%$ & 0.3301 & 0.2636 & 0.1927 \\
\hline \multirow[t]{2}{*}{ SPREAD_EW } & Full universe & $\begin{array}{l}0.18 \% \\
(5.74)\end{array}$ & $0.89 \%$ & -0.3103 & 0.1052 & 0.3159 \\
\hline & Industry-neutral & $\begin{array}{l}0.14 \% \\
(4.66)\end{array}$ & $0.87 \%$ & -0.0774 & 0.1550 & 0.2565 \\
\hline
\end{tabular}

Note: Each week for the full-universe approach we sort all individual firms according to their values of SKEW (or SPREAD) into quintile portfolios and form a portfolio by buying the quintile with the lowest SKEW (or SPREAD) and shorting that with the highest. For the industry-neutral approach, in each industry with at least five firms per week, we sort stocks into quintiles according to the SKEW (or SPREAD) of each firm, buy the quintile with the lowest SKEW (or SPREAD), and short that with the highest. We then form a portfolio across all available industries during the week. The daily observations of SKEW and SPREAD are estimated by the averages of the implied volatilities, either weighted by option trading volume $(V W)$ or equally weighted $(E W)$. The numbers in parentheses are $t$-statistics.

risk and higher $t$-statistics and Sortino ratios than their industry-exposed, full-universe counterparts.

\section{PORTFOLIO PERFORMANCE OVER LONGER HOLDING PERIODS}

Previous studies have shown that the return predictability of volatility skew and volatility spread lasts for longer horizons. In this section, we sort firms based on the prior week's measures of SKEW_VW and SPREAD_VW and compute the equally weighted holding period returns for the subsequent four weeks, eight weeks, and so on, up to 25 weeks into the future. ${ }^{17}$ Exhibit 7 summarizes the performances of the full-universe and industry-neutral portfolios for the pair-trading strategy, with $n=2$ (panel A) and $n=3$ (panel B). It reports descriptive statistics of the annualized holdingperiod returns, including the mean, standard deviation, skewness, and (because of the overlapping returns) Newey-West [1987] $t$-statistics.
The industry-neutral portfolios sorted according to volatility skew always generate significant and positive returns and exhibit higher $t$-statistics, lower standard deviation, and higher return skewness than the fulluniverse portfolios for all horizons in both panels A and B. Hence, the industry-neutral portfolios sorted by SKEW dominate their full-universe counterparts for longer horizons.

Portfolios sorted by volatility spread exhibit a similar pattern. The annualized returns of industryneutral and full-universe portfolios are consistently significant and positive for all investment horizons in panels $\mathrm{A}$ and $\mathrm{B}$. The industry-neutral portfolios have higher $t$-statistics, lower standard deviation, and much less negative, or even positive, skewness than do the full-universe portfolios. Moreover, the average portfolio returns from industry-neutral approaches are consistently higher than those of industry-exposed ones, except for the longer horizons in panel B. Therefore, for longer investment horizons, industry-neutral portfolios sorted by SPREAD outperform the full-universe portfolios. 


\section{E X H I B I T 7}

Portfolio Performance with the Pair-Trading Strategy for Longer Holding Periods

\begin{tabular}{|c|c|c|c|c|c|c|c|}
\hline & \multirow[b]{2}{*}{ Weeks } & \multicolumn{3}{|c|}{ Industry Neutral } & \multicolumn{3}{|c|}{ Full Universe } \\
\hline & & Return & S.D. & Skewness & Return & S.D. & Skewness \\
\hline \multicolumn{8}{|c|}{ Panel A: Number of Selected Stocks in Each Industry $=2$} \\
\hline \multirow[t]{6}{*}{ SKEW_VW } & 4 & $\begin{array}{l}8.15 \% \\
(3.09)\end{array}$ & $4.51 \%$ & 0.1618 & $\begin{array}{l}7.04 \% \\
(1.61)\end{array}$ & $6.61 \%$ & 0.0282 \\
\hline & 8 & $\begin{array}{l}6.79 \% \\
(2.98)\end{array}$ & $6.60 \%$ & 0.1568 & $\begin{array}{l}6.04 \% \\
(1.62)\end{array}$ & $9.42 \%$ & -0.2302 \\
\hline & 12 & $\begin{array}{l}6.73 \% \\
(3.56)\end{array}$ & $8.23 \%$ & 0.0857 & $\begin{array}{l}6.51 \% \\
(1.98)\end{array}$ & $11.73 \%$ & -0.1925 \\
\hline & 16 & $\begin{array}{l}7.08 \% \\
(4.00)\end{array}$ & $9.72 \%$ & 0.1403 & $\begin{array}{l}7.09 \% \\
(2.33)\end{array}$ & $13.56 \%$ & -0.0900 \\
\hline & 20 & $\begin{array}{l}7.40 \% \\
(4.46)\end{array}$ & $11.26 \%$ & 0.2350 & $\begin{array}{l}7.29 \% \\
(2.55)\end{array}$ & $15.89 \%$ & -0.1236 \\
\hline & 25 & $\begin{array}{l}6.89 \% \\
(4.40)\end{array}$ & $12.67 \%$ & 0.1205 & $\begin{array}{l}7.39 \% \\
(2.84)\end{array}$ & $17.84 \%$ & -0.1998 \\
\hline \multirow[t]{6}{*}{ SPREAD_VW } & 4 & $\begin{array}{l}8.07 \% \\
(4.40)\end{array}$ & $3.10 \%$ & 0.6671 & $\begin{array}{l}7.89 \% \\
(2.96)\end{array}$ & $4.34 \%$ & 0.4955 \\
\hline & 8 & $\begin{array}{l}6.56 \% \\
(4.69)\end{array}$ & $4.43 \%$ & 0.4152 & $\begin{array}{l}6.37 \% \\
(3.09)\end{array}$ & $6.07 \%$ & 0.1066 \\
\hline & 12 & $\begin{array}{l}6.54 \% \\
(5.84)\end{array}$ & $5.26 \%$ & 0.1355 & $\begin{array}{l}6.52 \% \\
(4.04)\end{array}$ & $7.34 \%$ & -0.2055 \\
\hline & 16 & $\begin{array}{l}6.26 \% \\
(5.98)\end{array}$ & $6.23 \%$ & 0.2491 & $\begin{array}{l}5.89 \% \\
(4.25)\end{array}$ & $8.22 \%$ & -0.0015 \\
\hline & 20 & $\begin{array}{l}5.81 \% \\
(6.36)\end{array}$ & $7.05 \%$ & 0.2406 & $\begin{array}{l}5.75 \% \\
(4.63)\end{array}$ & $9.33 \%$ & 0.0197 \\
\hline & 25 & $\begin{array}{l}5.53 \% \\
(6.67)\end{array}$ & $8.00 \%$ & 0.4711 & $\begin{array}{l}5.42 \% \\
(4.94)\end{array}$ & $10.50 \%$ & -0.0032 \\
\hline \multicolumn{8}{|c|}{ Panel B: Number of Selected Stocks in Each Industry $=3$} \\
\hline \multirow[t]{6}{*}{ SKEW_VW } & 4 & $\begin{array}{l}6.46 \% \\
(3.00)\end{array}$ & $3.72 \%$ & 0.2086 & $\begin{array}{l}7.00 \% \\
(1.94)\end{array}$ & $5.42 \%$ & 0.0796 \\
\hline & 8 & $\begin{array}{l}5.21 \% \\
(2.72)\end{array}$ & $5.44 \%$ & 0.3495 & $\begin{array}{l}5.57 \% \\
(1.82)\end{array}$ & $7.63 \%$ & -0.1047 \\
\hline & 12 & $\begin{array}{l}5.34 \% \\
(3.26)\end{array}$ & $6.80 \%$ & 0.1370 & $\begin{array}{l}6.36 \% \\
(2.38)\end{array}$ & $9.43 \%$ & -0.0734 \\
\hline & 16 & $\begin{array}{l}5.61 \% \\
(3.63)\end{array}$ & $8.05 \%$ & 0.1794 & $\begin{array}{l}6.91 \% \\
(2.76)\end{array}$ & $11.11 \%$ & -0.0074 \\
\hline & 20 & $\begin{array}{l}5.76 \% \\
(3.90)\end{array}$ & $9.44 \%$ & 0.1822 & $\begin{array}{l}6.95 \% \\
(2.90)\end{array}$ & $13.21 \%$ & -0.0797 \\
\hline & 25 & $\begin{array}{l}5.45 \% \\
(3.88)\end{array}$ & $10.73 \%$ & 0.1036 & $\begin{array}{l}6.92 \% \\
(3.13)\end{array}$ & $14.89 \%$ & -0.0853 \\
\hline \multirow[t]{6}{*}{ SPREAD_VW } & 4 & $\begin{array}{l}6.34 \% \\
(4.29)\end{array}$ & $2.66 \%$ & 0.5376 & $\begin{array}{l}5.42 \% \\
(2.47)\end{array}$ & $3.59 \%$ & 0.2673 \\
\hline & 8 & $\begin{array}{l}5.04 \% \\
(4.39)\end{array}$ & $3.75 \%$ & 0.1742 & $\begin{array}{l}4.90 \% \\
(2.83)\end{array}$ & $5.10 \%$ & -0.0233 \\
\hline & 12 & $\begin{array}{l}4.72 \% \\
(5.08)\end{array}$ & $4.44 \%$ & -0.0361 & $\begin{array}{l}5.21 \% \\
(3.73)\end{array}$ & $6.07 \%$ & -0.2235 \\
\hline & 16 & $\begin{array}{l}4.52 \% \\
(5.31)\end{array}$ & $5.22 \%$ & 0.0246 & $\begin{array}{l}4.82 \% \\
(4.05)\end{array}$ & $6.94 \%$ & -0.0621 \\
\hline & 20 & $\begin{array}{l}4.34 \% \\
(5.78)\end{array}$ & $5.90 \%$ & 0.0693 & $\begin{array}{l}5.00 \% \\
(4.65)\end{array}$ & $7.84 \%$ & -0.0594 \\
\hline & 25 & $\begin{array}{l}4.32 \% \\
(6.39)\end{array}$ & $6.57 \%$ & 0.3326 & $\begin{array}{l}4.80 \% \\
(5.02)\end{array}$ & $8.83 \%$ & 0.0052 \\
\hline
\end{tabular}

Note: The return refers to the annualized average return over time, and S.D. refers to the standard deviation. The numbers in parentheses are the Newey-West (1987) t-statistics. 


\section{CONCLUSION}

Academic research into the return predictability of volatility skew and volatility spread typically involves sorting over a full universe of stocks, regardless of their industries. However, industry effects are a key indicator in stock evaluation and portfolio construction for finance practitioners. For example, equity fund managers often restrict the active positions in their investment portfolios to industry-neutral stocks. Moreover, there is evidence that industry risk is orthogonal to common risk factors and should be considered in pricing stock portfolios (e.g., Bali et al. [2006]).

Using data on stocks and stock options from January 1996 to December 2011, we show that conventional portfolio strategies based on sorting the full universe of stocks according to volatility skew and volatility spread are exposed to heavy industry effects. By neutralizing industry effects, we can reduce portfolio risk, especially downside risk, and improve portfolio performance. Moreover, industry-neutral portfolios exhibit superior performance, not only over the following week, but also over longer holding horizons. The evidence substantiates the necessity of constructing industry-neutral portfolios when using option information to sort stocks. In addition, the returns that the industry-neutral approach generates are more stable than those of the conventional approach during periods of market turbulence, because the full-universe portfolios were heavily exposed to the IT sector during the dot-com bubble crash and to the finance sector during the recent banking crisis. Our study contributes to the asset pricing and portfolio investment literature and invokes future research to theoretically model industry factors into the pricing of individual stock options.

\section{ENDNOTES}

The authors thank Frank Fabozzi and an anonymous referee for helpful comments and suggestions. The authors also thank Zheng Chen for providing excellent research assistance. Zhang gratefully acknowledges the financial supports from the Research Committee of Lingnan University (grant number DR12B3) and from the government of the HKSAR (grant number LU 342412).

${ }^{1}$ See, for example, Bali and Hovakimian [2009]; Bollerslev et al. [2009]; Cremers and Weinbaum [2010]; Xing et al. [2010]; Yan [2011]; Han and Zhou [2012]; Jin et al. [2012]; Rehman and Vilkov [2012]; and Conrad et al. [2013].
${ }^{2}$ The Sortino ratio measures the average return per unit of downside risk, where downside risk is the absolute negative deviation from the mean.

${ }^{3}$ The equity options listed at the CBOE are American options. The methodology the Ivy DB database adopts to compute implied volatilities considers an early exercise premium.

${ }^{4}$ Cremers and Weinbaum [2010] define volatility spread as the ATM call-implied volatility, minus the ATM putimplied volatility, that is, $\mathrm{IV}_{\mathrm{C}, \mathrm{ATM}}-\mathrm{IV}_{\mathrm{P}, \mathrm{ATM}}$. The resulting estimates are mostly negative. We use $\mathrm{IV}_{\mathrm{P}, \mathrm{ATM}}-\mathrm{IV}_{\mathrm{C}, \mathrm{ATM}}$ to ensure that the measure is positive and consistent with volatility skew, which is often positive.

${ }^{5}$ In a robustness test, we construct the market valueweighted portfolios and find qualitatively similar results.

${ }^{6}$ In the United States, the options market closes later than the underlying stock markets do. The measurement errors created by non-synchronous asset and option prices can be partly offset, because volatility skew and volatility spread are the differences between the implied volatilities of call and put options on the same trading day.

${ }^{7} \mathrm{We}$ choose two-digit SIC codes because the number of firms with traded equity options in each industry is limited.

${ }^{8}$ To obtain N80, each week we sort industries according to net exposure, from the highest to the lowest, and compute the proportion of industries for which the accumulated net exposure just reaches or exceeds $80 \%$ of the total net exposure.

${ }^{9} \mathrm{We}$ find that the most frequently represented industries with the highest net exposure are electronic and electrical equipment, except computer equipment (SIC code 36); holding and other investment offices (SIC code 67), and business services (SIC code 73). However, these industries change over time. For example, for SKEW, business services (SIC code 73) and electronic equipment (SIC code 36) often had the highest industry net exposure during the dot-com bubble crash, from 1999 to 2001. During the banking crisis, from 2008 to the end of our sample period, the holding and other investment offices sector (SIC code 67) most often had the highest net exposure for both SKEW and SPREAD.

${ }^{10}$ In their pair-trading strategy, Bali et al. [2006] choose to buy one stock and sell one stock in each industry $(n=1)$ to form industry-neutral stock portfolios. When we use optionimplied measures to select stocks, the number of industries is limited in each week. To achieve sufficient diversification, we include more stocks in each industry by setting $n=2$ or $n=3$.

${ }^{11} \mathrm{We}$ include the third moment of the return distribution for reference only. 
${ }^{12}$ The weekly drawdown is defined as the largest decline in the weekly cumulative return from the first to the current week, and reflects a portfolio's downside risk.

${ }^{13} \mathrm{An}$ earlier version of our article uses data from January 1996 to June 2007. The pair-trading portfolio $(n=2)$ constructed with the full-universe approach based on SKEW_ EW has a $t$-statistic of 2.25 and a standard deviation of $1.66 \%$. The extended sample reduces the $t$-statistic greatly, and the weekly returns from 2008 to 2011 are very volatile, due to the banking crisis.

${ }^{14}$ Each week, the sample to construct the full-universe portfolios starts from all firms, while that for industry-neutral portfolios considers only industries with at least five firms. Considering a smaller sample makes it more difficult for the industry-neutral approach to outperform the full-universe approach. As a robustness test, we use the sample of industries with at least five firms in a week to construct industry-exposed portfolios and find that, for all cases of SKEW and SPREAD, the industry-exposed portfolios thus formed always generate lower $t$-statistics and Sortino ratios than their industry-neutral counterparts do.

${ }^{15}$ For the pair-trading strategy, we find that during the three-year period from 1999 to 2001 and the four-year period from 2008 to 2011, industry-neutral portfolios always have higher $t$-statistics and Sortino ratios than their corresponding full-universe portfolios, for both SKEW and SPREAD.

${ }^{16}$ As discussed (in footnote 14 ), each week the full-universe approach starts from all firms, while the industry-neutral portfolios are from industries with at least five firms. Therefore, in addition to starting from a smaller sample, industryneutral portfolios formed by a quintile-based strategy always involve fewer stocks than do full-universe portfolios. The inclusion of fewer stocks tends to result in higher portfolio standard deviations (Statman [1987]). As a robustness test, we find that the industry-exposed portfolios, formed by only industries with no fewer than five firms in a week, consistently generate lower $t$-statistics and Sortino ratios than do their corresponding industry-neutral portfolios.

${ }^{17}$ Untabulated results show that, when firms are sorted based on SKEW_EW or SPREAD_EW, the industry-neutral portfolios also outperform the industry-exposed, full-universe portfolios for longer holding periods. The results are available upon request.

\section{REFERENCES}

Bali, T., and A. Hovakimian. "Volatility Spreads and Expected Stork Returns." Management Science, 55 (2009), pp. 17971812.
Bali, T., K. Demirtas, A. Hovakimian, and J. Merrick, Jr. "Peer Pressure: Industry Group Impacts on Stock Valuation Precision and Contrarian Strategy Performance." The Journal of Portfolio Management, 32 (2006), pp. 80-92.

Bollerslev, T., G. Tauchen, and H. Zhou. "Expected Stock Returns and Variance Risk Premia." Review of Financial Studies, 22 (2009), pp. 4463-4492.

Conrad, J., R. Dittmar, and E. Ghysels. "Ex Ante Skewness and Expected Stock Returns." The Journal of Finance, 68 (2013), pp. 85-124.

Cremers, M., and D. Weinbaum. "Deviations from Put-Call Parity and Stock Return Predictability." The Journal of Financial and Quantitative Analysis, 45 (2010), pp. 335-367.

Daniel, K., and S. Titman. "Testing Factor-Model Explanations of Market Anomalies." Critical Finance Review, 1 (2012), pp. 103-139.

Doran, J., and K. Krieger. "Implications for Asset Returns in the Implied Volatility Skew." Financial Analysts Journal, 66 (2010), pp. 65-76.

Driessen, J., P. Maenhout, and G. Vilkov. "The Pricing of Correlation Risk: Evidence from Equity Options." Journal of Finance, 64 (2009), pp. 1377-1406.

Easley, D., M. O'Hara, and P. Srinivas. "Option Volume and Stock Prices: Evidence on Where Informed Traders Trade." Journal of Finance, 53 (1998), pp. 431-465.

Gârleanu, N., L. Pedersen, and A. Poteshman. "DemandBased Option Pricing." Review of Financial Studies, 22 (2009), pp. 4259-4299.

Han, B., and Y. Zhou. "Variance Risk Premium and CrossSection of Stock Returns." Working paper, University of Toronto, 2012

Jin, W., J. Livnat, and Y. Zhang. "Option Prices Leading Equity Prices: Do Option Traders Have an Information Advantage?" Journal of Accounting Research, 50 (2012), pp. 401-432.

Longin, F., and B. Solnik. "Extreme Correlation of International Equity Markets." Journal of Finance, 56 (2001), pp. 649-676. 
Moskowitz, T. "An Analysis of Covariance Risk and Pricing Anomalies.” Review of Financial Studies, 16 (2003), pp. 417-457.

Moskowitz, T., and M. Grinblatt. "Do Industries Explain Momentum?” Journal of Finance, 54 (1999), pp. 1249-1290.

Newey, W., and K. West. "A Simple, Positive Semi-Definite, Heteroskedasticity and Autocorrelation Consistent Covariance Matrix.” Econometrica, 55 (1987), pp. 703-708.

Pollet, J., and M. Wilson. "Average Correlation and Stock Market Returns.” Journal of Financial Economics, 96 (2010), pp. 364-380.

Rehman, Z., and G. Vilkov. "Risk-Neutral Skewness: Return Predictability and Its Sources." Working paper, Goethe University, 2012.

Statman, M. "How Many Stocks Make a Diversified Portfolio?" Journal of Financial and Quantitative Analysis, 22 (1987), pp. 353-363.

Xing, Y., X. Zhang, and R. Zhao. "What Does the Individual Option Volatility Smirk Tell Us about Future Equity Returns?" Journal of Financial and Quantitative Analysis, 45 (2010), pp. 641-662.

Yan, S. "Jump Risk, Stock Returns, and Slope of Implied Volatility Smile." Journal of Financial Economics, 99 (2011), pp. 216-233.

Zhang, Y. "Individual Skewness and the Cross-Section of Average Stock Returns.” Working paper, Yale University, 2005.

To order reprints of this article, please contact Dewey Palmieri atdpalmieri@iijournals.com or 212-224-3675. 